\title{
Peran Pendidikan Terhadap Ekonomi Digital di Indonesia
}

\section{Neni Retnahayati $\mathbf{i}^{*}$}

${ }^{1}$ Statistisi Muda, Badan Pusat Statistik

\section{Informasi Artikel \\ Sejarah artikel: \\ Diterima November 2018 \\ Disetujui November 2018 \\ Dipublikasikan Maret \\ 2019}

\section{Keywords:}

Digital Ekonomic,

Education,

Internet

\begin{abstract}
ABS TRACT
At present, the digital economy is considered as a sector that is able to sustain economic growth in the future. However, whether the development of digital technology has been balanced with the level of education that has been received by the population in Indonesia. Therefore, increasing and equalizing the quality of human resources is an important key to succeeding in the digital economy era. This study aims to determine the effect of educational variables on internet use by companies/businesses in Indonesia on 2016. The education variables referred to in this study are pure primary school enrollment rates, junior high school enrollment rates, high school pure enrollment rates, number of public tertiary institutions, percentage student number, and number of teachers. The method used in this study is quantitative descriptive analysis with classical regression analysis (ordinary least square). The results of the study show that there is a relationship between the junior high school enrollment rate and the percentage of students to the population of internet use by companies / businesses in Indonesia. Therefore, investment in education is an important component to support the development of the digital economy. With investment in education, human resources will have better skills and experience.
\end{abstract}




\section{PENDAHULUAN}

Perkembangan ekonomi digital memberikan prospek yang sangat besar dagi dunia perekonomian, dan mempengaruhi berbagai sektor usaha seperti energi, perbankan, perdagangan, percetakan, transportasi, pendidikan, kesehatan, dan media (Bank Dunia, 2016). Definisi singkat dari ekonomi digital adalah kegiatan ekonomi yang didukung oleh teknologi digital (Alam et al., 2018). Penggunaan teknologi digital merupakan salah satu faktor pendorong terpenting terhadap pertumbuhan ekonomi (Mohamed et al., 2010).

Penggunaan internet merupakan salah satu aspek dari teknologi digital. Berdasarkan Survei Aplikasi Pengguna Jasa Internet Indonesia, penguna internet pada tahun 2017 sebanyak 143,26 juta jiwa. Bila dibandingkan dengan tahun 2016, terjadi peningkatan pengguna internet sebesar 7,37 persen. Berdasarkan data yang dikeluarkan oleh Badan Pusat Statistik, total penduduk Indonesia pada tahun 2017 sebanyak 262 juta jiwa. Hal tersebut menunjukkan bahwa saat ini sebesar 54,68 persen penduduk indonesia mengakses internet.

Maraknya penggunaan internet dimanfaatkan oleh dunia usaha untuk memasarkan produknya (Iswahyudi, M. \& Iqbal, A., 2018). Pengusaha memanfaatkan teknologi digital maupun media sosial untuk menjual produk barang dan jasa, serta transaksi dan berkomunikasi langsung antar perusahaan ataupun individu (Margaret, J.R., 2018). Selain itu, pengusaha juga memanfaatkan media internet untuk mencari perkembangan pasar.

Berdasarkan data BPS, pada tahun 2016 terdapat 26,71 juta usaha/perusahaan. Jumlah tersebut meningkat dibandingkan dengan hasil sensus ekonomi yang dilakukan pada tahun 2006, yaitu sebanyak 22,73 juta usaha/perusahaan. Perusahaan yang memanfaatkan internet dalam jual maupun beli produk sebesar 2,67 persen, sedangkan perusahaan yang memanfaatkan internet selain untuk jual atau beli sebesar 2,47 persen. Peningkatan jumlah pengguna internet menunjukkan bahwa pengaruh generasi milenial terhadap dunia usaha sangat kuat (Iswahyudi, M. \& Iqbal, A., 2018). Generasi milenial ditandai dengan akrabnya penggunaan teknologi digital dan media sosial.

Saat ini, ekonomi digital dianggap sebagai sektor yang mampu menopang pertumbuhan ekonomi dimasa yang akan datang (Himawan, 2017). Di indonesia, kegiatan ekonomi digital sudah mulai berkembang, terutama di kota besar seperti Jakarta, Bandung, Surabaya, dan Medan. Akan tetapi apakah perkembangan teknologi digital telah diimbangi dengan tingkat pendidikan yang telah diterima oleh penduduk di Indonesia.

Meskipun ekonomi digital memiliki dampak yang baik untuk pertumbuhan ekonomi, tetapi penerapan ekonomi digital yang berpusat di wilayah tertentu saja justru berpotensi menimbulkan masalah kesenjangan antarwilayah yang makin lebar. Ekonomi digital akan berkembang bila didukung oleh kesiapan sarana dan prasarana, serta kesiapan sumber daya manusia sebagai pengguna dan pengkreasi kegiatan ekonomi digital.

Hasil penelitian ini diharapkan dapat memberikan gambaran mengenai perbandingan antarwilayah pemanfaatan ekonomi digital di Indonesia, dan juga kaitannya dengan variabel pendidikan. Variabel pendidikan yang dimaksud yaitu: angka partisipasi murni SD, angka partisipasi murni SMP, angka partisipasi murni SMA, jumlah perguruan tinggi negeri, persentase mahasiswa terhadap jumlah penduduk, dan jumlah guru. Dengan begitu, dapat disusun strategi pembangunan SDM yang mendukung peningkatan dan pemerataan penerapan ekonomi digital di Indonesia.

\section{KAJIAN TEORI DAN EMPIRIK}

Penelitian ini untuk membuktikan teori Kuznets. Dalam teorinya, Kuznets 
menyatakan bahwa ketika peranan sektor industri semakin meningkat, maka terjadi pergeseran dari sektor pertanian ke sektor industri modern termasuk industri pengolahan dan jasa (Kim, 2014).

Selain itu terdapat penelitian yang dilakukan oleh Hanuskek dan Kimko (2000) yang meneliti tentang pengaruh pendidikan dan kualitas tenaga kerja terhadap pertumbuhan ekonomi. Hasil penelitiannya menunjukkan bahwa kualitas tenaga kerja yang diukur dengan indikator banyaknya jumlah tahun sekolah yang dimiliki pekerja memberikan pengaruh positif terhadap pertumbuhan ekonomi.

Penelitian yang dilakukan oleh Ridwan (2017) tentang pengaruh human capital terhadap pertumbuhan ekonomi regional di Provinsi Jawa Tengah. Dalam penelitiannya dikemukakan bahwa tenaga kerja memiliki pengaruh yang signifikan terhadap pertumbuhan ekonomi.

\section{METODE PENELITIAN}

Metode penelitian yang digunakan adalah analisis deskriptif kuantitatif dengan menggunakan analisis regresi klasik (Ordinary Least Square). Hasil regresi dari penelitian ini kemudian di deskripsikan. Dalam analisis regresi klasik, data yang digunakan harus memenuhi asumsi klasik, yaitu: uji asumsi klasik multikolineriritas, heteroskedastisitas, autokorelasi, dan normalitas (Makosolang dkk, 2015).

Yang dimaksud dengan uji asumsi klasik multikolinearitas yaitu suatu kondisi dimana dua atau lebih variabel prediktor pada multiple linier regression berkorelasi. Masalah multikolinieritas seringkali membuat hasil analisis regresi menjadi tidak sesuai atau bertentangan dengan teori (Sunaryo, 2011).

Uji heteroskedastisitas digunakan untuk melihat apakah terdapat ketidaksamaan varians dari residual satu ke pengamatan ke pengamatan yang lain (Umar, 2014). Uji autokorelasi digunakan untuk mengetahui apakah dalam sebuah model regresi linier terdapat hubungan yang kuat baik positif maupun negatif antar data yang ada pada variabel-variabel penelitian (Umar, 2014). Uji normalitas dilakukan untuk mengetahui apakah variabel dependen, independen atau keduanya berdistribusi normal, mendekati normal atau tidal (Umar, 2014).

Data yang digunakan dalam penelitian ini adalah data sekunder tahun 2016 , yaitu data persentase usaha/perusahaan yang memanfaatkan media internet, angka partisipasi murni SD, angka partisipasi murni SMP, angka partisipasi murni SMA, jumlah perguruan tinggi negeri, persentase mahasiswa terhadap jumlah penduduk, dan jumlah guru di 34 provinsi di Indonesia.

Angka partisipasi murni SD, yaitu persentase jumlah anak pada kelompok usia 7-12 tahun yang sedang bersekolah pada jenjang pendidikan SD terhadap jumlah seluruh anak pada kelompok usia sekolah SD (BPS, 2018).

Angka partisipasi murni SMP, yaitu persentase jumlah anak pada kelompok usia 13-15 tahun yang sedang bersekolah pada jenjang pendidikan SMP terhadap jumlah seluruh anak pada kelompok usia sekolah SMP (BPS, 2018).

Angka partisipasi murni SMA, yaitu persentase jumlah anak pada kelompok usia 16-18 tahun yang sedang bersekolah pada jenjang pendidikan SMA terhadap jumlah seluruh anak pada kelompok usia sekolah SMA (BPS, 2018)

Secara matematis, hubungan antara variabel pendidikan yang mempengaruhi persentase penggunaan internet oleh usaha/perusahaan di Indonesia digambarkan dalam fungsi berikut:

$$
\begin{aligned}
& \text { P-Internet } i=\alpha_{0}+\alpha_{1} \text { LnPTN }_{i}+\alpha_{2} P_{-} \text {MHS }_{i}+ \\
& \alpha_{3} \text { LnGuru }_{i}+\alpha_{4} \text { APM_SD } \\
& +\alpha_{6} \text { APM_SMA } \alpha_{5} \text { APM_SMP } P_{i}
\end{aligned}
$$

Dimana P-Internet merupakan persentase perusahaan/usaha yang menggunakan in- 
ternet, PTN adalah jumlah perguruan tinggi negeri, $\mathrm{P} \_\mathrm{MHS}$ adalah persentase mahasiswa terhadap jumlah penduduk, Guru adalah jumlah guru, APM_SD adalah angka partisipasi murni SD, APM_SMP adalah angka partisipasi murni SMP, APM_SMA adalah angka partisipasi murni SMA, $\alpha_{0}$ adalah intersep, $\alpha_{1}, \alpha_{2}, \alpha_{3}, \alpha_{4}, \alpha_{5}, \alpha_{6}$ adalah koefisien regresi, $e_{i}$ adalah residu, dan $i$ adalah provinsi (Aceh,...., Papua)

\section{PEMBAHASAN}

Berdasarkan data Badan Pusat Statistik, Provinsi Jawa Barat dan Jawa Timur sebagai provinsi yang memiliki jumlah usaha yang memanfaatkan internet untuk jual atau beli tertinggi, yaitu 125.224 usaha dan 124.483 usaha. Provinsi Maluku merupakan provinsi yang memiliki jumlah usaha dengan memanfaatkan internet untuk jual beli paling sedikit yaitu 1.129 usaha.

Selain untuk jual beli, perusahaan juga memanfaatkan internet sebagai media komunikasi untuk mencari perkembangan pasar. Provinsi Jawa Timur dan Jawa Barat sebagai provinsi yang memiliki jumlah usaha yang memanfaatkan internet selain untuk jual atau beli tertinggi, yaitu 118.621 usaha dan 112.290 usaha.
Grafik 1. memberikan informasi bahwa selain banyak perusahaan/usaha yang telah menggunakan internet, tetapi ada disparitas regional dalam penggunaan internet oleh perusahaan/usaha, baik itu penggunaan internet untuk jual/beli dan juga untuk selain jual/beli. Disparitas regional dalam penggunaan internet bisa disebabkan oleh beberapa hal, seperti: perbedaan penguasaan modal, perbedaan kualitas sumber daya manusia, dan perbedaan distribusi infrastruktur teknologi informasi (Sujarwoto \&Tampubolon, 2016).

Grafik 2 menunjukkan bahwa provinsi yang menggunakan internet sebagai media untuk jual/beli, perusahaan/usaha tersebut juga memanfaatkan internet selain untuk jual/beli seperti media komunikasi.

Setelah dilakukan pengolahan maka didapat nilai $R 2=0,8256$. Nilai $R 2$ sebesar 0,8256 sehingga dapat disimpulkan bahwa terdapat hubungan yang erat antara penggunaan internet sebagai media untuk menjual produk barang dan jasa dengan penggunaan internet sebagai media komunikasi untuk mencari informasi perkembangan pasar.

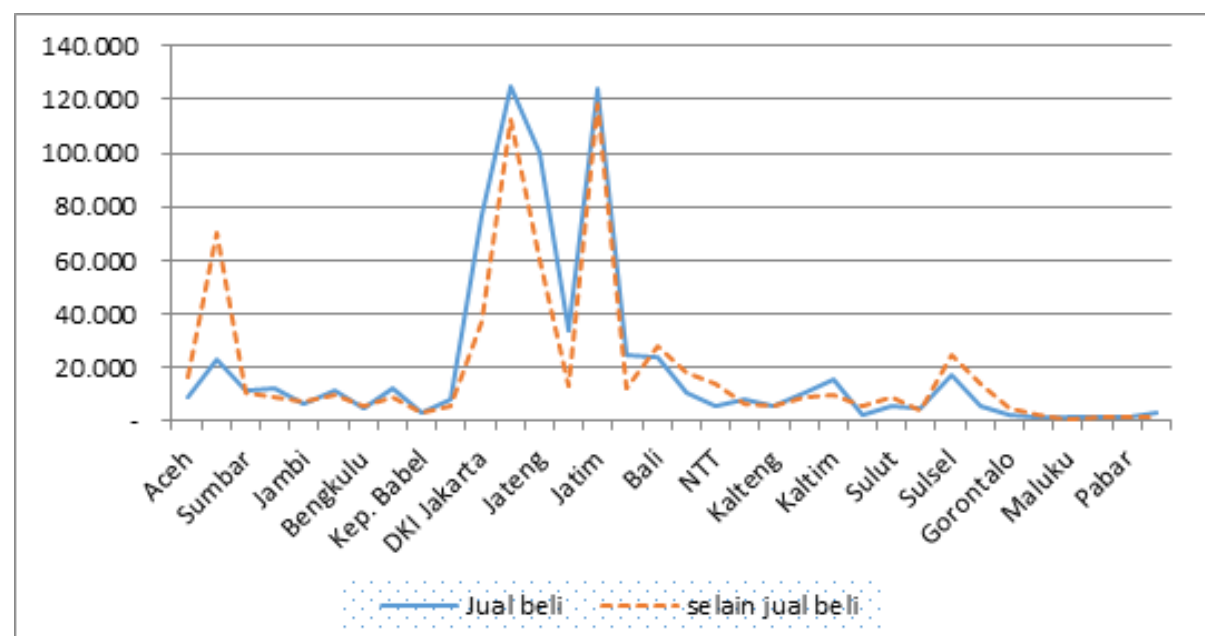

\section{Gambar 1. Banyaknya Perusahaan Pengguna Internet untuk Jual/beli dan Selain Jual Beli di 34 Provinsi Tahun 2016 \\ Sumber: Hasil Pendaftaran Usaha/Perusahaan Sensus Ekonomi 2016 Indonesia, BPS}




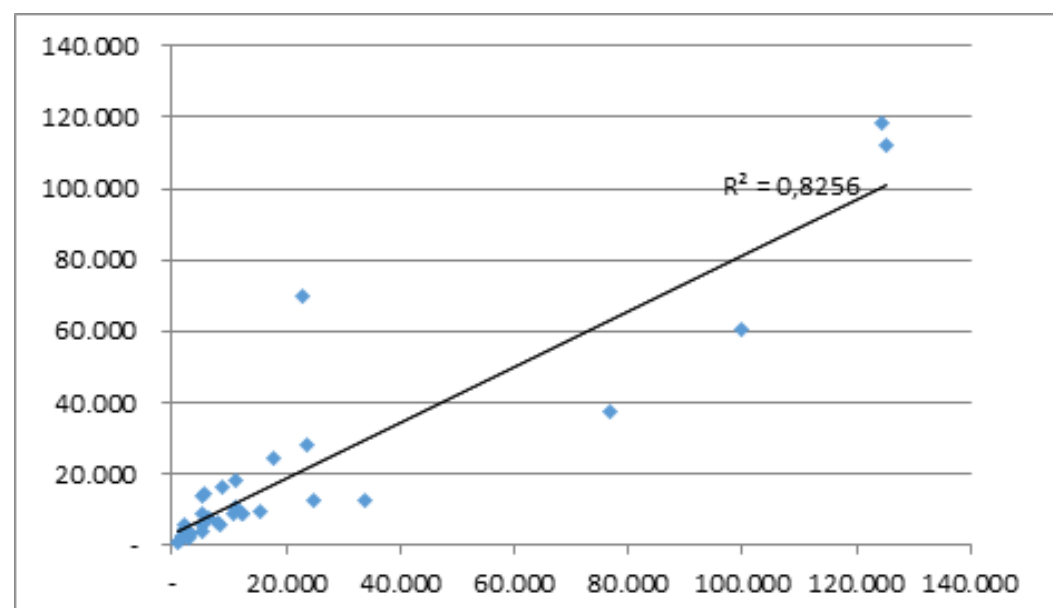

Gambar 2 Pengaruh Penggunaan Internet Sebagai Media Jual/beli dan selain Sumber: data diolah.

\section{Jual Beli di 34 Provinsi Tahun 2016}

Sebelum melakukan analisis regresi berganda, variabel yang akan digunakan harus memenuhi asumsi klasik. Yang pertama dilakukan adalah uji autokorelasi, diperoleh hasil olah pada tabel 1. dengan menggunakan derajat kepercayaan $5 \%$, maka disimpulkan bahwa model ini tidak memiliki gejala autokorelasi. Pada uji normalitas diperoleh hasil pada tabel 2.

Tabel 1

Uji Autokorelas

\begin{tabular}{cccccc}
\hline Model & $\mathrm{R}$ & $\mathrm{R}$ Square & $\begin{array}{c}\text { Adjusted } \mathrm{R} \\
\text { Square }\end{array}$ & $\begin{array}{c}\text { Std. Error of the } \\
\text { Estimate }\end{array}$ & Durbin-Watson \\
\hline 1 &, $727^{\mathrm{a}}$ &, 529 &, 420 & 1,6471253 & 1,755 \\
\hline
\end{tabular}

a. Predictors: (Constant), MSNSP, InGuru, APM_SD, APM_SMA, InPTN, APM_SMP

b. Dependent Variable: inet_p

Tabel 2

Uji Normalitas

\begin{tabular}{lccccccc}
\hline & N & Mean & Std. Deviation & \multicolumn{2}{c}{ Skewness } & \multicolumn{2}{c}{ Kurtosis } \\
& Statistic & Statistic & Statistic & Statistic & Std. Error & Statistic & Std. Error \\
\hline inet_p & 34 & 5,341659 & 2,6637923 & 1,582 &, 403 & 2,999 &, 788 \\
APM_SD & 34 & 96,128235 & 3,5434613 & $-3,869$ &, 403 & 18,372 &, 788 \\
APM_SMP & 34 & 75,805588 & 6,4444170 & $-1,171$ &, 403 & 2,509 &, 788 \\
APM_SMA & 34 & 60,982647 & 6,1686044 &,- 511 &, 403 &, 842 &, 788 \\
InGuru & 34 & 2,152765 &, 1042781 &,- 190 &, 403 &,- 471 &, 788 \\
InPTN & 34 &, 9542 &, 79202 &, 387 &, 403 &,- 457 &, 788 \\
MSNSP & 33 & 2,488 & 1,8953 & 3,124 &, 409 & 10,077 &, 798 \\
Valid N (listwise) & 33 & & & & & & \\
\hline
\end{tabular}


Kesimpulan yang diperoleh dari tabel 2, karena rasio skewness dan rasio kurtosis (Statistics/Std. Error) berada di antara -2 hingga +2 , maka disimpulkan bahwa distribusi data adalah normal. Pada uji heteroskedatisitas, didapat peroleh hasil pada tabel 3. jumlah guru terhadap persentase penggunaan internet oleh perusahaan/usaha di Indonesia. Dari hasil uji statistik, diperoleh hanya variabel angka partisipasi murni SMP dan persentase mahasiswa terhadap jumlah penduduk yang berpengaruh signifikan terhadap persentase penggunaan internet oleh perusahaan/usaha di Indonesia.

Tabel 3

Uji Heteroskedatisitas

\begin{tabular}{|c|c|c|c|c|c|c|}
\hline & \multirow[t]{2}{*}{ Model } & \multicolumn{2}{|c|}{$\begin{array}{l}\text { Unstandardized } \\
\text { Coefficients }\end{array}$} & \multirow{2}{*}{$\begin{array}{c}\text { Standardized } \\
\text { Coefficients } \\
\text { Beta } \\
\end{array}$} & \multirow[t]{2}{*}{$\mathrm{t}$} & \multirow[t]{2}{*}{ Sig. } \\
\hline & & $B$ & Std. Error & & & \\
\hline 1 & (Constant) & 16,733 & 12,981 & & 1,289 & 209 \\
\hline & $\begin{array}{l}\text { APM_SD } \\
\text { APM_SMP } \\
\text { APM_SMA } \\
\text { InPTN } \\
\text { InGuru } \\
\text { MSNSP }\end{array}$ & $\begin{array}{c}-, 110 \\
, 220 \\
, 000 \\
, 944 \\
-9,050 \\
, 358\end{array}$ & $\begin{array}{c}, 125 \\
, 104 \\
, 081 \\
, 503 \\
4,588 \\
, 164\end{array}$ & $\begin{array}{l}-, 180 \\
, 666 \\
-, 001 \\
, 343 \\
-, 412 \\
, 313\end{array}$ & $\begin{array}{c}-, 880 \\
2,110 \\
-, 004 \\
1,877 \\
-1,973 \\
2,179 \\
\end{array}$ & $\begin{array}{l}, 387 \\
, 045 \\
, 997 \\
, 072 \\
, 059 \\
, 039\end{array}$ \\
\hline
\end{tabular}

a. Dependent Variable: inet_p

Berdasarkan tabel di atas maka dapat disimpulkan bahwa tidak semua nilai t-statistik dari variabel pejelas ada yang signifikan secara statistik, sehingga dapat disimpulkan bahwa model ini tidak mengalami heteroskedastisitas.

Pada uji multikolinearitas diperoleh hasil bahwa terdapat beberapa variabel penjelas yang memiliki nilai VIF lebih besar 10 maka dapat disimpulkan bahwa model regresi ini memiliki masalah multikolinieritas.

Dalam penelitian ini dilakukan juga pengujian variabel pendidikan, seperti: angka partisipasi murni SD, angka partisipasi murni SMP, angka partisipasi murni SMA, jumlah perguruan tinggi negeri, persentase mahasiswaterhadapjum lah penduduk, dan
Secara matematis, hubungan antara variabel pendidikan yang mempengaruhi persentase penggunaan internet oleh perusahaan/usaha di Indonesia digambarkan dalam fungsi berikut:

P-Interneti $=\alpha_{0}+\alpha_{1}$ APM_SMP $P_{i}+\alpha_{2} P_{-}$ $\mathrm{MHS}_{i}+\mathrm{e}_{i}$

Dimana P-Internet merupakan persentase perusahaan/usaha yang menggunakan internet, APM SMP adalah angka partisipasi murni SMP, P_MHS adalah persentase mahasiswa terhadap jumlah penduduk, $\alpha_{0}$ adalah intersep, $\alpha_{1}, \alpha_{2}$ adalah koefisien regresi, $e_{i}$ adalah residu, dan i adalah provinsi (Aceh,...., Papua)

Tabel 4

Hasil Penelitian

\begin{tabular}{ll}
\hline \multicolumn{1}{c}{ Variabel Penelitian } & Hasil Uji Statistik \\
\hline APM SD & Tidak signifikan \\
APM SMP & Signifikan \\
APM SMA & Tidak signifikan \\
Jumlah guru & Signifikan \\
Jumlah mahasiswa & Signifikan \\
Jumlah perguruan tinggi negeri & Tidak Signifikan \\
\hline Sumber:
\end{tabular}


Setelah dilakukan uji regresi linier berganda, maka didapat nilai koefisien sebagai berikut:

$\boldsymbol{\alpha}_{1}=0,223$ menunjukkan jika ada kenaikan angka partisipasi murni SMP sebesar satu persen maka akan menyebabkan kenaikan persentase perusahaan/usaha yang menggunakan internet sebesar 0,223 persen.

$\boldsymbol{\alpha}_{\mathbf{2}}=0,350$ menunjukkan jika ada kenaikan persentase mahasiswa terhadap jumlah penduduk sebesar satu persen maka akan menyebabkan kenaikan persentase perusahaan/usaha yang menggunakan internet sebesar 0,350 persen. berikut:

Sehingga didapat fungsi sebagai

P-Interneti $=\alpha_{0}+0,223$ APM_SMP $P_{i}+0,350$ $P_{-} \mathrm{MHS}_{i}+e_{i}$

Dengan mempertimbangkan peranan ekonomi digital terhadap pertumbuhan ekonomi yang terus bertambah setiap tahunnya, maka strategi-strategi untuk meningkatkan ekonomi digital perlu dilakukan oleh setiap daerah. Hasil penelitian menunjukkan bahwa persentase perusahaan/usaha yang menggunakan internet dipengaruhi oleh angka partisipasi murni SMP dan persentase mahasiswa terhadap jumlah penduduk disuatu wilayah di Indonesia. Hal ini membuktikan bahwa perkembangan ekonomi digital di suatu daerah dipengaruhi oleh kondisi pendidikan.

Oleh karena itu, investasi di bidang pendidikan merupakan komponen penting untuk mendukung perkembangan ekonomi digital. Dengan investasi di bidang pendidikan maka akan didapatkan sumber daya manusia yang memiliki keterampilan dan pengalaman yang lebih baik.

Untuk mengurangi ketimpangan regional dalam perkembangan ekonomi digital perlu dilakukan langkah-langkah khusus oleh daerah dengan penggunaan inernet untuk kegiatan perusahaan/usaha yang rendah agar bisa menyusul dengan wilayah lain yang lebih maju. Daerah-daerah ini sebaiknya berusaha untuk meningkatkan APM SMP setinggi mungkin sebagai strategi jangka pendek. Hal ini karena pembiayaan dan penyediaan sarana dan prasarana SMP lebih ringan dari upaya untuk meningkatkan persentase penduduk yang menjadi mahasiswa.

Lalu sebagai strategi jangka panjang adalah melakukan upaya-upaya yang dapat mendukung peningkatan persentase pendududuk yang menjadi mahasiswa atau berkuliah di perguruan tinggi. Hal ini bisa dilakukan dengan pemberian beasiswa untuk melanjutkan pendidikan ke perguruan tinggi bagi lulusan SMA yang berprestasi tetapi tidak memiliki kemampuan finansial. Juga perlu untuk menyediakan akses fisik infrastruktur yang lebih baik bagi perguruan tinggi yang ada agar masyarakat lebih tertarik untuk melanjutkan pendidikan.

\section{KESIMPULAN DAN SARAN}

Berdasarkan hasil pembahasan maka dapat disimpulkan bahwa terdapat hubungan yang erat antara penggunaan internet sebagai media untuk menjual/ membeli produk barang dan jasa dengan penggunaan internet sebagai media komunikasi untuk mencari informasi perkembangan pasar. Hasil penelitian juga menunjukkan bahwa persentase perusahaan/ usaha yang menggunakan internet dipengaruhi oleh angka partisipasi murni SMP dan persentase mahasiswa terhadap jumlah penduduk disuatu wilayah di Indonesia. Hal ini membuktikan bahwa perkembangan ekonomi digital di suatu daerah dipengaruhi oleh kondisi pendidikan.

Saran untuk penelitian yang akan datang, agar dampak jangka panjang dapat lebih terlihat maka sebaiknya digunakan analisis data panel. Selain itu, dapat dilakukan penelitian untuk variabel lain yang mempengaruhi kegiatan ekonomi digital seperti variabel indikator ekonomi 
masyarakat, dan ketersediaan infrastruktur teknologi informasi.

\section{DAFTAR PUSTAKA}

Alam, K., Erdiaw-Kwasie, M., Shahiduzzaman, M. and Ryan, B. 2018, Assessing regional digital competence: digital futures and strategic planning implications, Working Paper, University of Southern Queensland, Toowoomba.

Asosiasi Pengguna Jasa Internet Indonesia. Infografis Penetrasi dan Perilaku Pengguna Internet Indonesia 2017. Jakarta.

Badan Pusat Statistik. 2017. Hasil Pendaftaran Usaha/Perusahaan Sensus Ekonomi 2016 Indonesia. Jakarta.

Badan Pusat Statistik. 2018. Statistik Indonesia 2018. Jakarta.

Bank Dunia. 2016. Digital Dividends: World Development Report 2016, The World Bank, Washington, DC.

Hanushek, EA., Kimko, DD. 2010. Schooling, Labor-Force Quality, And The Growth Of Nations. The American Economic Review, Vol. 90, No. 5 : 1184-1208

Himawan, M. A. 2015. Perancangan Sosial Media Marketing bagi Dinas Perdagangan dan Perindustrian dalam Mempromosikan Usaha Mikro Kecil dan Menengah di Kota Surabaya. Jurnal Teknik ITS, 2017; 5(2).

Kim, O. O. 2014. The Ukraine and China International Trade Cooperation Impact on The UkrainebTrade Deficit. Journal of Life Economics, 2014:1(2):17-24 DOI 10.15637/jlecon.33.

Lubis, Tona Aurora dan Junaidi. 2016. Pemanfaatan Teknologi Informasi pada Usaha Mikro Kecil dan Menengah di Kota Jambi. Jurnal Perspektif Pembiayaan dan Pembangunan Daerah Vol. 3 No. 3, Januari-Maret 2016.

Makosolang, dkk. 2015. Analisis Hetero- skedatisitas pada data cross section dengan white Heteroscedasticity Test dan Weighted Least Squares. JdC, Vol. 4, No. 2, September 2015.

Margaret, J. R. 2018. Pengaruh Promosi Berbasis Teknologi Informasi Terhadap Pengusaha Muda Universitas Klabat. Cogito Smart Journal, Vol.4, No.1, June 2018.

Maulana, Ridwan. 2015. Pengaruh Human Capital Terhadap Pertumbuhan Ekonomi Regional di Provinsi Jawat Tengah. Economic Development Analysis Journal, 4(2), 159-165.

Mirawati, Ira. 2015. Media Konsultasi Online Sebagai Alternatif Upaya Penanganan Masalah Remaja. Techno.com, Vol. 12, No. 1, Februari 2013: 29-44.

Mohamed, M., Murray, A. and Mohamed, M. 2010. The role of information and communication technology (ICT) in mobilization of sustainable development knowledge: a quantitative evaluation, Journal of Knowledge Management, Vol. 14 No. 5, 744-758.

Sujarwoto,S., Tampubolon,G. 2016. Spatial inequality and the Internet divide in Indonesia 2010-2012. Telecommunications Policy, http://dx.doi.org/ 10.1016/j. telpol.2015.08.008i.

Setiawan, S.S \& Siagian, T. H. 2011. Mengatasi Masalah Multikolinearitas dan Outlier dengan Pendekatan ROBDCA. Jurnal Matematika, Saint \& Teknologi, Volume 12, Nomor 1, Maret 2011, 1-10.

Umar, H. 2014. Metode Penelitian untuk Skripsi dan Thesis Bisnis. Jakarta: Regional Press. 